\title{
Effect of Design Parameters on Response Characteristics of Water Hydraulic Proportional Control Valves
}

\author{
F. Yoshida and S. Miyakawa \\ Basic Technology R \& D Center, KYB Corporation, \\ 1-12-1 Asamizodai, Minami-ku, Sagamihara-shi, Kanagawa-ken, Japan \\ E-mail: yoshida-fut@kyb.co.jp, miyakawa-shi@kyb.co.jp
}

\begin{abstract}
Water hydraulic proportional control valves using "tap water" as the working fluid are suitable for systems that require high levels of environmental friendliness and safety. Particularly, there are high expectations for their application to mining machinery, wave and wind power generation systems, and ocean development machinery, including underwater drilling machinery. In the previous report, the authors defined the transfer functions of three components of the water hydraulic proportional control valve, namely the compensation circuit, the solenoid, and the pilot valve, and experimentally and analytically examined the effects of design parameters on valve performance. In water hydraulic proportional control valves that use tap water, with its poor lubricating properties, as the working fluid, the hydrostatic bearings and damping orifices, which comprise the structural characteristics of the valve, function to ensure friction/wear prevention and stable operation of the spool. Moreover, the hydrostatic bearings and damping orifices structurally constitute a meter-in circuit that is effective in improving the response characteristics of the spool and a meter-out circuit that is effective in improving the damping characteristics of the spool; their functions are determined depending on the purpose of the valve. This report focuses on the open loop transfer function represented by the solenoid and the pilot valve and how that function effects the characteristics of the entire valve; more specifically, the effect of the geometric parameters of the hydrostatic bearings and damping orifices is examined; then, the effect of these parameters on the step response characteristics of the entire valve is analytically verified.
\end{abstract}

Keywords: Water hydraulic proportional control valve, tap water, response characteristics

\section{Introduction}

Water hydraulic proportional control valves using "tap water" as the working fluid are suitable for systems that require high levels of hygiene and safety; they can be used in a wide range of applications, including foods, beverages, semiconductors, medicines, pharmaceuticals, cosmetics, chemicals, natural energy technologies, and underwater applications. In particular, there are high expectations for their application to systems that require high levels of safety and environmental friendliness, for instance, mining machinery, wave and wind power generation systems, and ocean development machinery, including underwater drilling machinery, as well as systems requiring high levels of hygiene and washing performance in the automation of meat/seafood processing, which has been conventionally performed manually.

In the previous report, the authors defined the transfer functions of three components of the water hydraulic proportional control valve, namely the compensation circuit, the solenoid, and the pilot valve, and experimentally and analytically examined the effects of design parameters on valve performance [2], [3], [4]. A water hydraulic proportional control valve using tap water with low lubricating properties as the working fluid has a structure in which hydrostatic bearings support the spool at both ends for friction/wear prevention; damping orifices generate damping force for stable spool operation by guiding fluid flowing from the hydrostatic bearings to the pressure chambers at the both ends of the spool. From their positional relationship, the hydrostatic bearings and damping orifices constitute a meter-in circuit and a meter-out circuit for spool operation, respectively. Since the meter-in circuit effectively improves the response characteristics of the spool and the meter-out circuit effectively improves the damping characteristics of the spool; their functions are determined depending on the purpose. Their dimensions need to be optimally set for stable valve operation; however, consideration of the dimensions has been conducted only empirically, not theoretically.

This report focuses on the open loop transfer function that is represented by the solenoid and the pilot valve and how it 
affects the characteristics of the entire valve; more specifically, the effect of the geometric parameters, is examined. Then, the effect of these parameters on the entire valve in terms of its response characteristics is verified. Specifically, the dimensional ratio of the damping orifice diameter $\boldsymbol{D}_{\boldsymbol{n}}$ against the hydrostatic bearing equivalent orifice diameter $\boldsymbol{D}_{\boldsymbol{b}^{\prime}}$ is defined as $\boldsymbol{C r}=\boldsymbol{D}_{\boldsymbol{n}} / \boldsymbol{D}_{\boldsymbol{b}^{\prime}}$, the effect of changes in $\boldsymbol{C r}$ on the first-order lag time constant of the pilot valve $T_{L}$ and on the second-order lag damping coefficient of the solenoid and the pilot valve $\boldsymbol{\zeta}$, and the effect of $\boldsymbol{C r}$ on the step response of the loop transfer function of the entire valve including the compensation circuit are analytically examined.

\section{Overview of the water hydraulic proportional control valve}

This section describes the structural characteristics and control method of the water hydraulic proportional control valve.

\subsection{Structure}

Figure 1 shows the structure of the water hydraulic proportional control valve. Table 1 shows its major specifications. Low-viscosity tap water used as the working fluid makes it difficult to form water film in the clearance of the sliding member. For this reason, the water hydraulic proportional control valve has a structure in which hydrostatic bearings support the spool at both ends so that the spool can be displaced without contacting the sleeve to reduce friction/wear caused by sliding. Damping orifices are provided at both ends of the spool between the pressure chambers and the return line. This allows stable valve operation by providing damping force for spool operation. The spool is set in place by balancing between the solenoid thrust and the spring force. While a typical solenoid valve has a structure in which the solenoid and a compression spring support the spool at both ends, the water hydraulic proportional control valve instead uses an extension spring. The use of the extension spring frees the other end of the spool, allowing more effective hydrostatic bearing operation for reduced moment and lateral force.

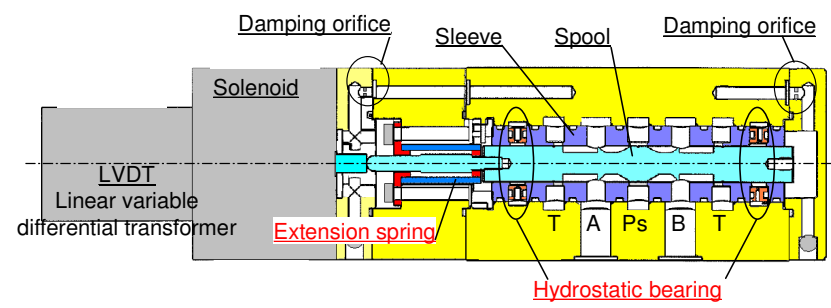

Figure 1: Structure
Table 1 Specifications

\begin{tabular}{|lc|c|}
\hline \multicolumn{2}{|c|}{ Item } & Specification \\
\hline Rated flow rate & {$[\mathrm{L} / \mathrm{min}]$} & 20 \\
\hline Rated pressure $\quad[\mathrm{MPa}]$ & 14 \\
\hline Operating pressure range $[\mathrm{MPa}]$ & 3.5 to 14 \\
\hline Operating temperature range $[\mathrm{deg} \mathrm{C}]$ & 2 to 50 \\
\hline Working fluid & Tap water \\
\hline Input voltage & {$[\mathrm{V}]$} & $+/-10$ \\
\hline
\end{tabular}

\subsection{Functions of the hydrostatic bearing orifices and damping orifices}

Figure 2 schematically shows the positional relationship between the spool, hydrostatic bearing orifice, and damping orifice. Since the hydrostatic bearing orifices function to support the spool in the sleeve so that it does not make contact with the sleeve and thus prevent friction/wear, the design dimensions of the orifices are determined by the load capacity required to retain the spool [1]. Fluid passing through the hydrostatic bearing orifices is guided to the pressure chambers at the ends of the spool; then, it passes through the damping orifices, generating damping force. The design dimensions of the damping orifices depend on the design dimensions of the hydrostatic bearing orifices; therefore, they cannot be uniquely determined. In addition to supporting the spool without coming into contact with it, as is apparent from the orifices positional relationship with the spool, the hydrostatic bearing orifices function as a meter-in circuit that effectively improves the response characteristics of the spool. Meanwhile, the damping orifices function as a meter-out circuit that effectively improves the damping characteristics of the spool. Which of the meter-in circuit or the meter-out circuit has a larger effect on spool operation depends on the relative relationship between the two types of orifices, the hydrostatic bearing orifices and the damping orifices. That is, if the hydrostatic bearing orifices are relatively smaller than the damping orifices, the effect as a meter-in circuit becomes larger; if the damping orifices are relatively and sufficiently larger than the hydrostatic bearing orifices, the effect as a meter-out circuit becomes larger. When the two circuits have an equal relationship, the effects of the meter-in and meter-out circuits are combined and considered to affect the spool.

Generally, the viscosity of water is very small (one thirtieth that of oil); thus, it is assumed that when water is used as the working fluid, the damping orifice diameter needs to be very small to generate sufficient damping force. From a practical point of view, making the damping orifice diameter smaller may increase the effect of contamination; however, almost no quantitative study has been made to such effect. In this regard for the water hydraulic proportional control valve, we studied the friction factor required to calculate the damping force of the damping orifices by comparing it with a case in which oil is used as the working fluid, instead of water. First, the relationship between the orifice diameter $\boldsymbol{D}$ and the Reynolds number $\boldsymbol{R} \boldsymbol{e}$ is calculated by using the orifice 
dimensions and the actual measured flow rate [2]. For example, when the orifice diameter is $\varphi 0.6$, in the case of water, the Reynolds number that produces turbulent flow is about 9,000, while, in the case of oil, the Reynolds number that produces laminar flow is about 300. This means that, even though the orifice diameter is the same, the type of flow differs depending on the working fluid type, water or oil. Next, fig. 3 shows the relationship between the Reynolds number $\boldsymbol{R} \boldsymbol{e}$ and the friction factor $\lambda$. In the case of oil, a friction factor $\lambda_{\text {Oil }}$ of 0.22 is obtained by applying $\lambda=$ 64/Re derived from the Hagen-Poiseuille law for laminar flow. In the case of water, a friction factor $\lambda_{\text {Water }}$ of 0.033 is obtained by applying the Blasius equation for turbulent flow. Thus, it is found that the friction factor in the case of water is about one sixth that of oil. Based on these results, fig. 4 shows the damping force in the case of water vs. oil calculated with common orifice diameters. From these results, to obtain the equivalent damping force, the orifice diameter in the case of water needs to be about half of that in the case of oil. However, making the orifice diameter smaller requires more precise boring and stricter contamination control in terms of mass production. Therefore, it is desirable to have a configuration combining the effects of a meter-in circuit and of a meter-out circuit, as proposed in this report.

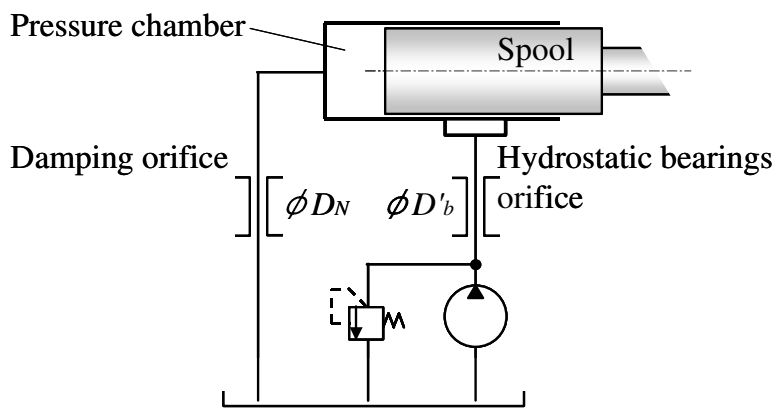

Figure 2: Physical relationship between the hydrostatic bearing orifice and the damping orifice

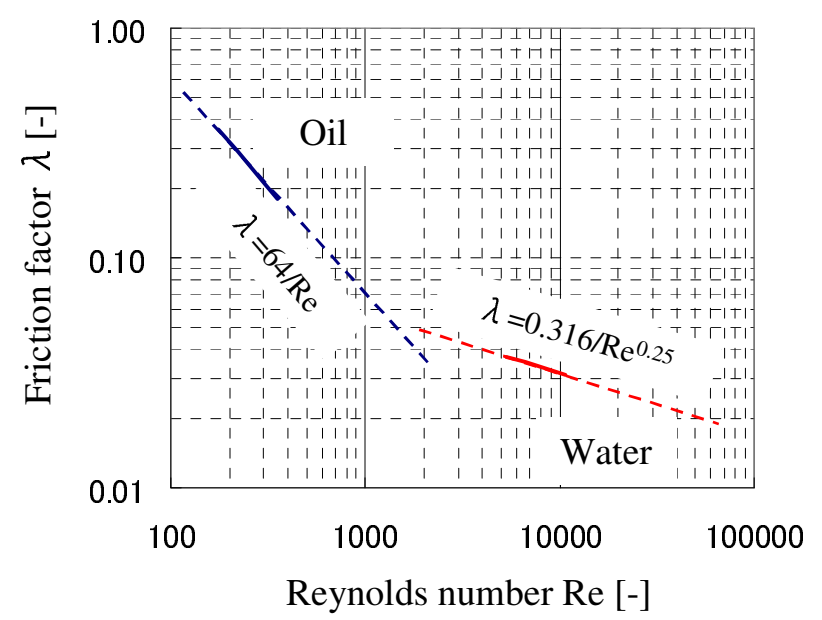

Figure 3: Relationship between the Reynolds number and the friction factor

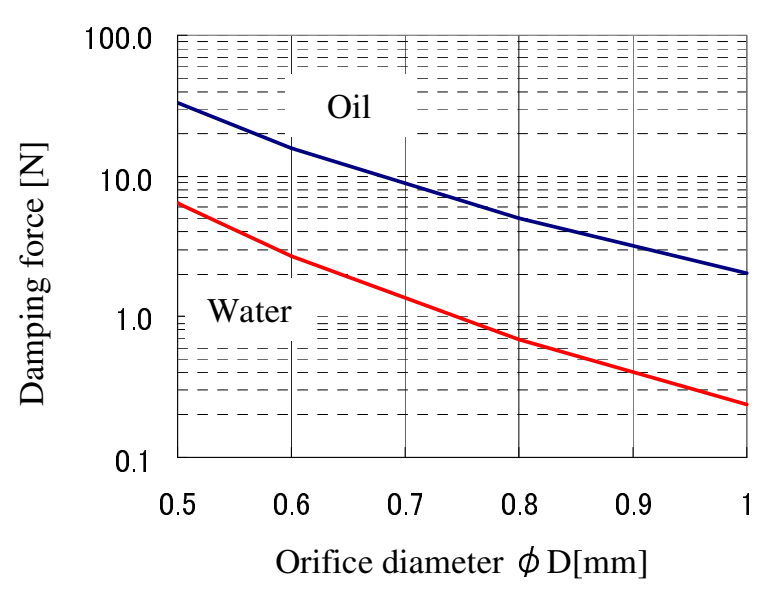

Figure 4: Relationship between the orifice diameter and the damping force

\subsection{Control method}

Figure 5 shows the block diagram of the valve system. The water hydraulic proportional control valve consists of three components: the compensation circuit, the solenoid, and the pilot valve. Their transfer functions are expressed as $C(s)$, $\boldsymbol{S}(\boldsymbol{s})$, and $\boldsymbol{P}(\boldsymbol{s})$. Valve control is performed by detecting spool displacement by the linear variable differential transformer (LVDT) and feeding it back to the compensation circuit of the PI controller.

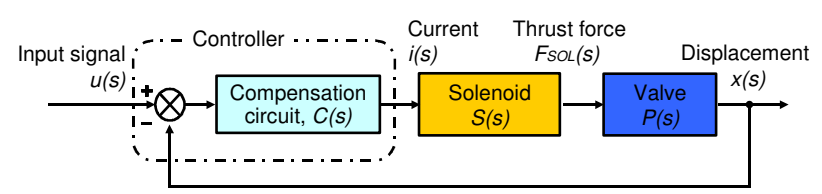

Figure 5: Block diagram of the valve system

\section{Transfer functions}

Figure 6 shows the parameter definition for the analytical model.

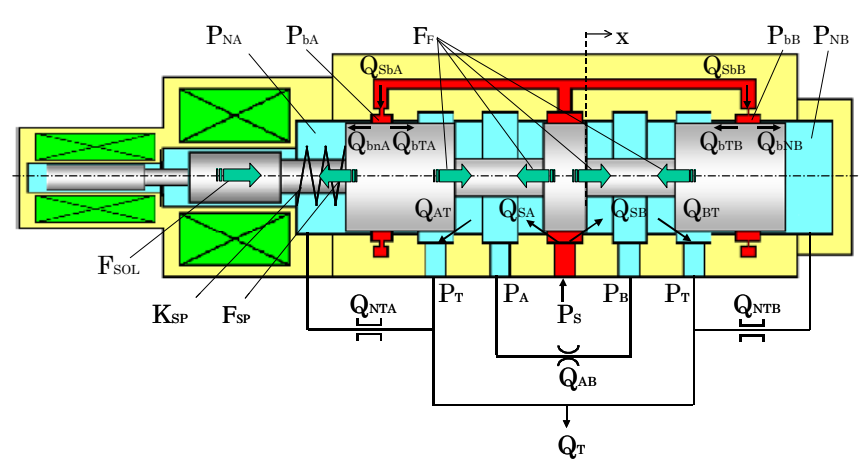

Figure 6: Parameter definition

As described above, the water hydraulic proportional control valve consists of three components: the compensation circuit, 
the solenoid, and the pilot valve. The compensation circuit is defined by eq. (1) with a standard PI controller.

$$
C(s)=\frac{k_{P} T_{I} s+k_{P}}{T_{I} s}
$$

Since it has been experimentally verified that the transfer function of the solenoid $S(s)$ can be approximated by a standard first-order lag transfer function in the previous report, it is defined by the transfer function in eq. (2). Figure 7 shows a comparison of the experimental results of the frequency characteristics of the solenoid thrust with the analytical results of the transfer function in eq. (2).

$$
S(s)=\frac{K_{S O L}}{\tau_{S O L} s+1}
$$
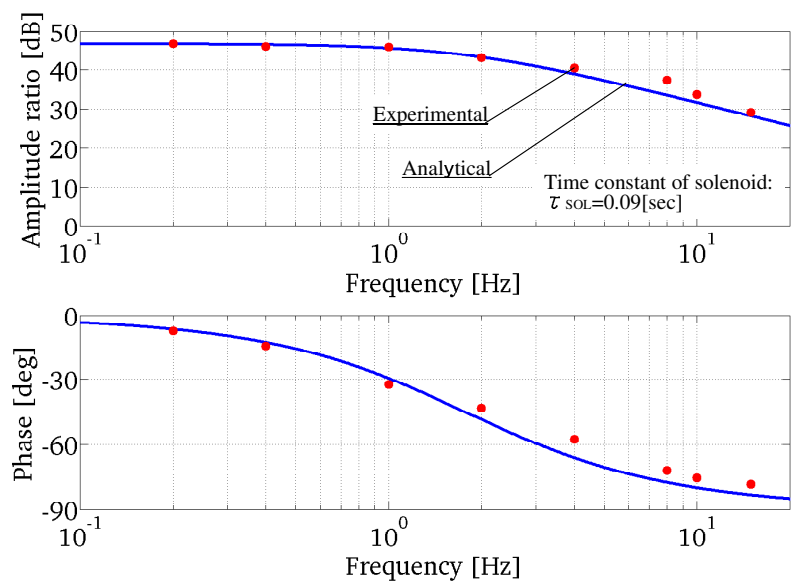

\section{Figure 7: The frequency characteristics of the solenoid thrust}

The transfer function of the pilot valve $\boldsymbol{P}(\boldsymbol{s})$ can be obtained as the first-order lag transfer function in eq. (3) by Laplace, transforming the mathematical model that linearizes the pressure and flow rate of each component in the vicinity of experimental points. Parameters in eq. (3) are defined by eq. (4) to eq. (19). In eq. (15), $\boldsymbol{C r}$ is the ratio of the damping orifice diameter against the hydrostatic bearing orifice diameter. Since four hydrostatic bearings are provided in the circumferential direction of the spool, they are expressed as the hydrostatic bearing equivalent orifice diameter $\boldsymbol{D}_{\boldsymbol{b}^{\prime}}$ as one orifice defined by eq. (14), and the ratio is expressed as $\boldsymbol{C r}=\boldsymbol{D}_{\boldsymbol{n}} / \boldsymbol{D}_{\boldsymbol{b}}$. From the measured flow rate and the Reynolds number calculated from the geometry, the flow from the hydrostatic bearing orifice was assumed to be laminar flow, and therefore, the orifice is modeled as a choke orifice by eq. (12). The friction factor $\lambda$ that determines the damping force of the damping orifices is modeled by eq. (19) by applying the Blasius equation for turbulent flow, as described above.
The transfer characteristics of the solenoid and the pilot valve (excluding the compensation circuit) of the three components defined above are expressed as the open loop transfer function $\boldsymbol{V}(\boldsymbol{s})$ of the valve shown in the block diagram (fig. 8) by the second-order lag transfer function in eq. (20). The damping coefficient $\zeta$, the natural frequency $\omega$, and the proportionality constant $\boldsymbol{K}$ are defined by eq. (21) to eq. (23), respectively. Further, as shown in fig. 3, the loop transfer function of the feedback control valve system, including the compensation circuit, $V_{S Y S}(s)$ is a third-order lag transfer function as shown in eq. (24).

$$
\begin{aligned}
& P(s)=\frac{x(s)}{F_{S O L}(s)}=\frac{K_{L}}{T_{L} s+1} \\
& T_{L}=\frac{\Gamma-\xi}{K_{S P}+\beta} \\
& K_{L}=\frac{1}{K_{S P}+\beta} \\
& \Gamma=\left(L_{b n}+L_{b T}\right) \frac{2 \pi \cdot D_{S P L} \cdot \mu}{\delta} \\
& \xi=\frac{2 A^{2} S P L}{\alpha \cdot \alpha_{b N}} \\
& \beta=8 \cdot C \cdot L_{W} \cdot\left(P_{S}-P_{L}\right) \cot (\theta) \\
& \alpha=\frac{\alpha_{b N}}{\alpha_{b N}+\alpha_{b T}-\alpha_{b}}-\frac{\alpha_{N}}{\alpha_{b N}}-1 \\
& \alpha_{N}=\frac{\pi^{2} 2^{5} D_{b}^{5}}{16 \rho L_{N T} Q_{N T 0} \cdot \lambda} C_{r}^{5} \\
& \alpha_{b N}=\frac{\pi \cdot D_{S P L} \cdot \delta^{3}}{12 \cdot \mu \cdot L_{b N}} \\
& \alpha_{b}=\frac{\pi \cdot D_{b}^{4}}{32 \cdot \mu \cdot L_{b}} \\
& \alpha_{b T}=\frac{\pi \cdot D_{S P L} \cdot \delta^{3}}{12 \cdot \mu \cdot L_{b T}} \\
& D_{b}^{\prime}=2 D_{b} \\
& C_{r}=\frac{D_{N}}{D_{b}^{\prime}} \\
& D_{N}=2 C_{r} D_{b} \\
& R e=\frac{2 w D_{b}}{v} C_{r} \\
& w=\frac{4 Q_{N T 0}}{\pi \cdot 2^{2} D_{b}^{2}} \frac{1}{C_{r}^{2}}
\end{aligned}
$$




$$
\lambda=0.3164 \cdot\left(2 \frac{w D_{b}}{v}\right)^{-0.25} C_{r}^{-0.25}
$$

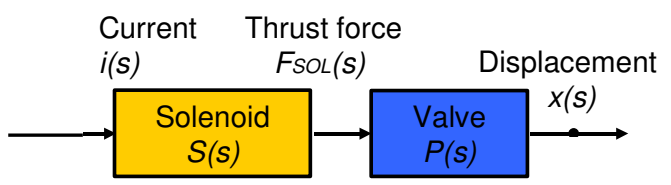

Figure 8: Block diagram of valve components excl. the compensation circuit

$$
\begin{aligned}
& V(s)=\frac{K \omega^{2}}{s^{2}+2 \varsigma \omega s+\omega^{2}} \\
& \omega=\sqrt{\frac{1}{T_{L} \cdot \tau_{S O L}}} \\
& \varsigma=\frac{1}{2}\left(\frac{1}{\tau_{S O L} \omega}+\tau_{S O L} \omega\right) \\
& K=\frac{K_{S O L}}{K_{S P}+\beta} \\
& V_{S Y S}(s)=\frac{k_{P} K \omega^{2}\left(s+\frac{1}{T_{I}}\right)}{s^{3}+2 \varsigma \omega s^{2}+\left(1+k_{P} K\right) \omega^{2} s+\frac{k_{P} K \omega^{2}}{T_{I}}}
\end{aligned}
$$

\section{Results and discussion}

Before finding out the characteristics of the entire valve, it is important to know the relationship between the transfer characteristics of the open loop transfer function shown in fig. 9 and $\boldsymbol{C r}$ defined as the equivalent diameter ratio of the damping orifice diameter against the hydrostatic bearing orifice diameter.

This section discusses the relationship between the time constant $\boldsymbol{T}_{\boldsymbol{L}}$ of the first-order lag transfer function $\boldsymbol{P}(\boldsymbol{s})$ of the pilot valve in eq. (3) and the damping coefficient $\zeta$ of the second-order lag transfer function $\boldsymbol{V}(\boldsymbol{s})$ of the solenoid and the pilot valve in eq. (20), with changes in $\boldsymbol{C r}$ defined as the equivalent diameter ratio of the damping orifice diameter against the hydrostatic bearing orifice diameter. Figure 9 shows the relationship between the damping coefficient $\zeta$ and $\boldsymbol{C r}$ that affects the time constant $\boldsymbol{T}_{\boldsymbol{L}}$.

\subsection{Effect of $\mathrm{Cr}$ on the transfer function $\mathrm{P}(\mathrm{s})$ of the pilot valve}

A $\boldsymbol{C r}$ larger than 1 suggests that the damping orifice diameter is relatively larger than the hydrostatic bearing orifice diameter. A $\boldsymbol{C r}$ smaller than 1 suggests that the damping orifice diameter is relatively smaller than the hydrostatic bearing orifice diameter.
Based on the above facts, the following relationship between the time constant $\boldsymbol{T}_{\boldsymbol{L}}$ of the transfer function of the pilot valve and $\boldsymbol{C r}$ are considered to be true.

- The smaller the $\boldsymbol{C r}$, the larger the time constant $\boldsymbol{T}_{\boldsymbol{L}}$ and the slower the pilot valve response. This suggests that the damping orifices have an effect as a meter-out circuit on spool operation.

- The larger the $\boldsymbol{C r}$, the smaller the time constant $\boldsymbol{T}_{\boldsymbol{L}}$ and the faster the pilot valve response. This suggests that the effect of the hydrostatic bearing orifices as a meter-in circuit is larger than the effect of the damping orifices as a meter-out circuit.

- As a general trend, in inverse proportion to an increase in the $\boldsymbol{C r}$, the time constant $\boldsymbol{T}_{\boldsymbol{L}}$ decreases, and the effect as a meter-out circuit on spool operation decreases rapidly. When the $\boldsymbol{C r}$ is larger than 1.2, the effect of the damping orifices is almost zero.

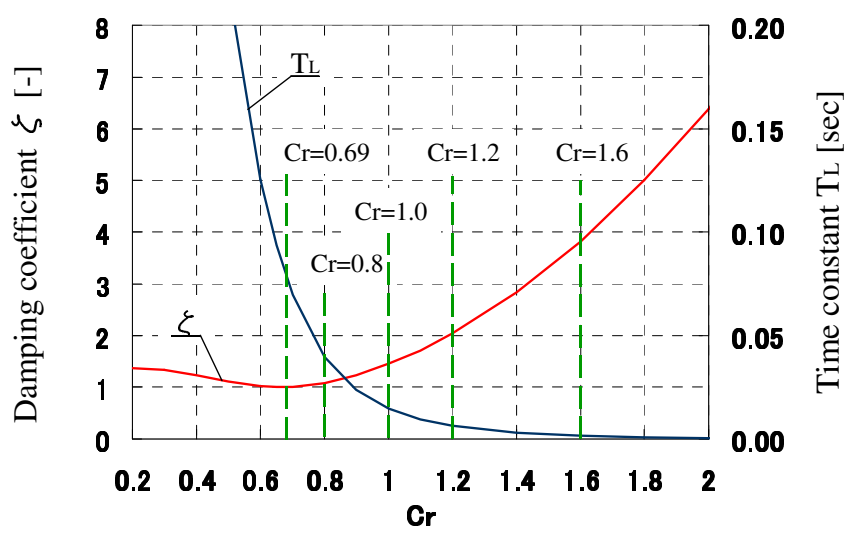

Figure 9: Relationship between the damping coefficient $\zeta$ and $\boldsymbol{C}_{\boldsymbol{r}}$ that affects the time constant $\boldsymbol{T}_{\boldsymbol{L}}$

\subsection{Effect of $\mathrm{Cr}$ on the transfer function $\mathrm{V}(\mathrm{s})$ that is expressed as the product of the pilot valve and the solenoid}

In fig. 9, the following relationship between the $\boldsymbol{C r}$ and the damping coefficient $\zeta$ of the open loop transfer function $V(s)$, expressed as the product of the pilot valve and the solenoid in eq. (4), are considered to be true.

- Regardless of the value of the $\boldsymbol{C r}, \boldsymbol{\zeta}$ is always positive. Thus, the transfer characteristics of the solenoid and the pilot valve (excluding the compensation circuit) are basically stable.

- When the $\boldsymbol{C r}$ is 0.69 , the damping coefficient $\boldsymbol{\zeta}$ becomes the minimum value 1 , which is the critical damping for a response that does not generate overshoot in the transient response.

- When $\zeta$ is larger than 1 , overdamping occurs, and the response slows down.

- In an exponential increase in the $\boldsymbol{C r}$, the damping coefficient $\zeta$ increases, and the level of the overdamping effect increases. 


\subsection{Effect of $\mathrm{Cr}$ on the step response characteristics of the open loop transfer function, excluding the compensation circuit}

Figure 10 shows the effect of the $\boldsymbol{C r}$ on the step response characteristics of the open loop transfer function when the $\boldsymbol{C r}$ is in the range from 0.69 to 1.6.

The smaller the $\boldsymbol{C r}$, the larger the time constant $\boldsymbol{T}_{\boldsymbol{L}}$ of the transfer function $\boldsymbol{P}(\boldsymbol{s})$, and the rise time tends to be fast.

The larger the $\boldsymbol{C r}$, the smaller the time constant $\boldsymbol{T}_{\boldsymbol{L}}$ of the transfer function $\boldsymbol{P}(\boldsymbol{s})$, and the rise time is fast. However, overdamping occurs due to increase in the damping coefficient $\zeta$ of the transfer function $V(s)$, not necessarily providing improvement in the response characteristics. When the $\boldsymbol{C r}$ is 1 or more, there is no significant difference in the stabilization time.

Based on the relationship described above, when the $\boldsymbol{C r}$ is small, the effect of the damping orifices as a meter-out circuit slows down the pilot valve response; when the $\boldsymbol{C r}$ is large, overdamping due to increase in the damping coefficient $\zeta$ slows down the response. Thus, the appropriate value of the $\boldsymbol{C r}$ is considered to be in the range from 0.69 to 1.6 .

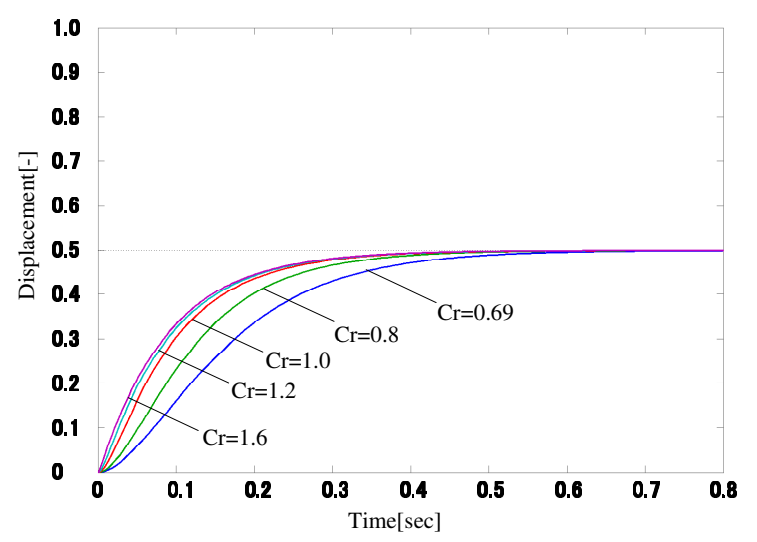

Figure 10: Effect of Cr on the step response characteristics of the open loop transfer function

\subsection{Effect of $\mathrm{Cr}$ on the step response characteristics of the loop transfer function}

The above results indicate that the $\boldsymbol{C r}$ has an appropriate range. It also indicates that the transfer characteristics that can be obtained from the thrust characteristics of the solenoid and the geometric structure of pilot valve are always stable. Overall, the water hydraulic proportional control valve constitutes a feedback control system, including the compensation circuit; the overall loop transfer function indicates the characteristics of the third-order lag transfer function in eq. (25). Figure 11 shows the effect of the $\boldsymbol{C r}$ on the step response characteristics of the loop transfer function. Based on this result, the effect of the compensation circuit was examined in terms of the step response characteristics of the valve system. Here, the $\boldsymbol{C r}$ is in the range from 0.69 to 1.6 ; the proportional gain of the compensation circuit $\boldsymbol{K}_{\boldsymbol{P}}$ is 1.9; the integral time $\boldsymbol{T}_{\boldsymbol{I}}$ is $0.1 \mathrm{sec}$.
When the $\boldsymbol{C r}$ is 0.69 , the rise time is slow, damped oscillation occurs, and convergence is slow. As the $\boldsymbol{C r}$ increases from 0.69 to 1 , both the rise time and convergence tend to be faster. Further, comparing the case where the $\boldsymbol{C r}$ is 1.2 with the case where the $\boldsymbol{C r}$ is 1.6, in the case of $\boldsymbol{C r}=$ 1.6 , the rise time is faster, but damping occurs rapidly, and the stabilization time is longer than in the case of $\boldsymbol{C r}=1.2$. Thus, the effect of the time constant $\boldsymbol{T}_{\boldsymbol{L}}$ on the rise time is considered to be large, and rapid damping occurs with the inflection point affected by the damping coefficient $\zeta$ when approaching the target value.

Figures 12 and 13 show the effect of the $\boldsymbol{C r}$ under different conditions of the proportional gain and integral time. In fig. 12, the proportional gain $\boldsymbol{K}_{\boldsymbol{P}}$ is 4 , and the integral time $\boldsymbol{T}_{\boldsymbol{I}}$ is $0.1 \mathrm{sec}$. In fig. 13, the proportional gain $\boldsymbol{K}_{\boldsymbol{P}}$ is 1.9 , and the integral time $\boldsymbol{T}_{\boldsymbol{I}}$ is 0.05 . Based on these results, the smaller the $\boldsymbol{C r}$, the slower the rise time under different conditions of the proportional gain and integral time; convergence proceeds as damped oscillation occurs. When the $\boldsymbol{C r}$ is too large, the rise time is fast, but the stabilization time tends to be lengthened.

Generally, the faster the rise time, the more likely overshoot occurs. However, this is not the case with the water hydraulic proportional control valve. As shown in fig. 10, the fast rise time is assumed to be achieved by the effect of the time constant $\boldsymbol{T}_{\boldsymbol{L}}$ of the transfer function $\boldsymbol{P}(\boldsymbol{s})$ of the pilot valve; the characteristics in the course of accessing the steady-state value and reaching convergence are assumed to be achieved by the effect of the damping coefficient $\zeta$ of the transfer function $V(s)$ of the solenoid and the pilot valve.

From the above results, in terms of rise time and damping characteristics, the $\boldsymbol{C r}$ is considered to have an optimum value in the range from 0.69 to 1.6. Appropriate values for the proportional gain and integral time of the compensation circuit need to be set in a certain range by considering both stable valve operation and good response characteristics.

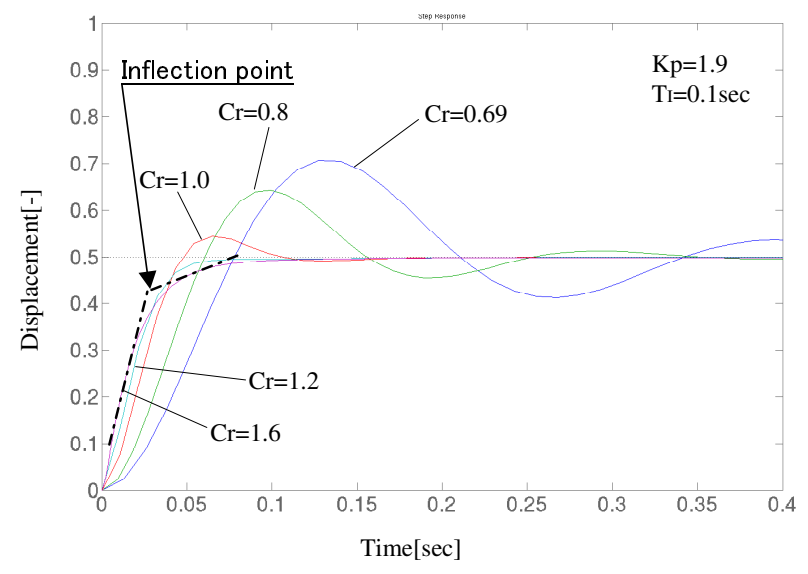

Figure 11: Effect of $\boldsymbol{C r}$ on the step response characteristics of the loop transfer function of the valve incl. the

compensation circuit

$\left(\boldsymbol{K}_{P}=1.9, \boldsymbol{T}_{I}=0.1 \mathrm{sec}\right)$ 


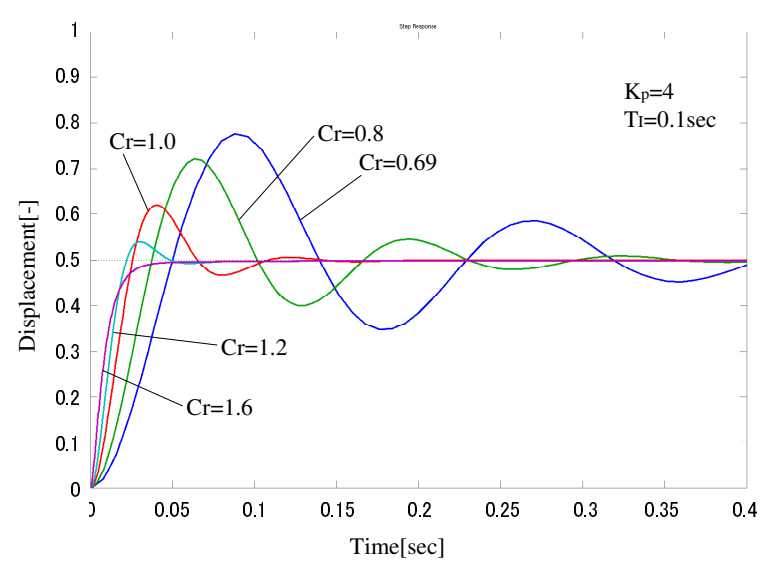

Figure 12: Effect of $\boldsymbol{C r}$ on the step response characteristics of the loop transfer function of the valve incl. the compensation circuit

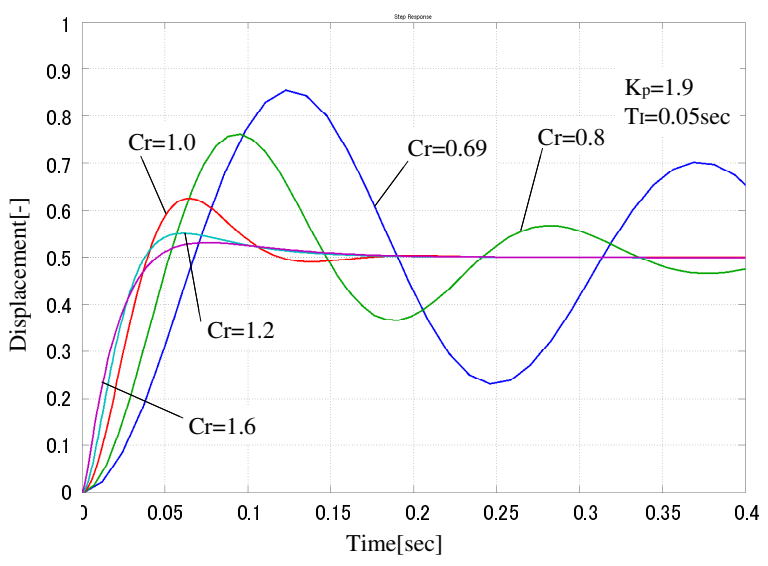

Figure 13: Effect of $\boldsymbol{C r}$ on the step response characteristics of the loop transfer function of the valve incl. the compensation circuit $\left(\boldsymbol{K}_{\boldsymbol{P}}=1.9, \boldsymbol{T}_{\boldsymbol{I}}=0.05 \mathrm{sec}\right)$

\section{Experimental verification}

From analytical verification in the previous section, it is found that the $\boldsymbol{C r}$ has a value that optimizes the step response characteristics in the range from 0.69 to 1.6 in terms of rise time and damping characteristics. This analytical result was experimentally verified.

\subsection{Experimental methods}

Figure 14 shows the schematic diagram of the experimental apparatus for step response characteristic verification. The experimental procedure is as follows. With the stop valve closed, the neutral point of the valve was adjusted. The difference between the load pressures at Port A and Port B $\boldsymbol{P}_{\boldsymbol{L}}$ was adjusted to $7 \mathrm{MPa}$ while opening the stop valve with an input signal of $50 \%$ input to the controller for experimental equilibrium. After adjusting the load pressure, the input signal was set to $0 \%$. For the waveform, stepwise input signals of $0 \%$ to $50 \%$ were input into the valve. The input signal $u$ and the spool displacement $x$ were chronologically recorded by the data logger. The experiment was conducted with supply pressure $\boldsymbol{P} \boldsymbol{s}$ at $14 \mathrm{MPa}$ and water temperature at $25 \pm 5^{\circ} \mathrm{C}$.

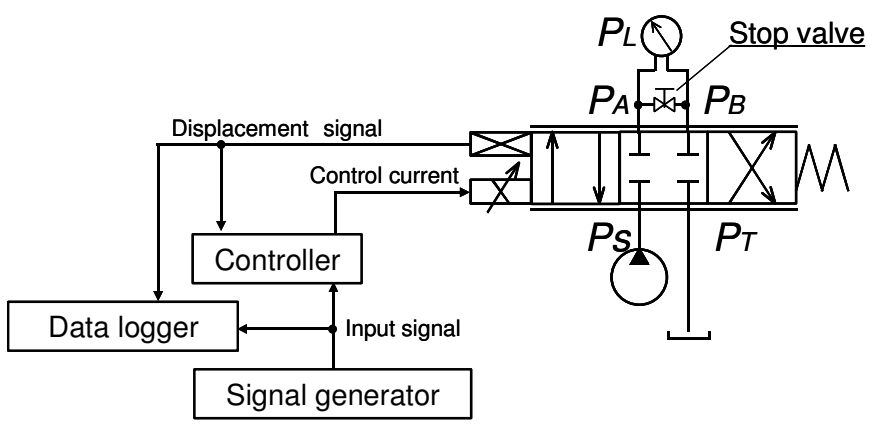

Figure 14: Schematic diagram of the experimental apparatus for step response characteristic verification

\section{2 Experimental results}

Figure 15 shows an example of the experiment where the effect of the $\boldsymbol{C r}$ on the step response characteristics was examined. Here, the parameters of the compensation circuit were adjusted to indicate the effect of the $\boldsymbol{C r}$ more clearly, and the spool displacement was normalized by removing steady-state errors. When the $\boldsymbol{C r}$ is 0.9 , the rise time to reach the steady-state value is relatively slow $(50 \mathrm{msec})$. When the $\boldsymbol{C r}$ is 2, the rise time is faster than for $\boldsymbol{C r}=0.9$; once about $95 \%$ of the target value is achieved, the slope of the curve becomes small at the inflection point before reaching the target value. It is assumed that the rise time is fast since the time constant $\boldsymbol{T}_{\boldsymbol{L}}$ is small when the $\boldsymbol{C r}$ is large, and at the inflection point and beyond, there is a damping effect of overdamping due to a large damping coefficient $\zeta$. The smaller the $\boldsymbol{C r}$, the slower the rise time; the larger the $\boldsymbol{C r}$, the faster the rise time, but the stabilization time is lengthened due to the damping effect of overdamping. These experimental results are similar to the analytical results.

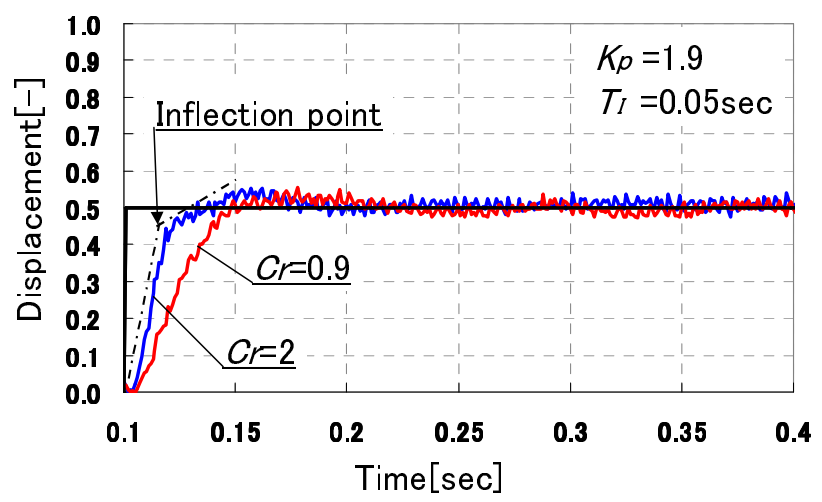

Figure 15: Experimental verification for the effect of $\boldsymbol{C r}$ on the step response characteristics

$$
\left(\boldsymbol{K}_{\boldsymbol{P}}=1.9, \boldsymbol{T}_{\boldsymbol{I}}=0.05 \mathrm{sec}\right)
$$




\section{Conclusions}

When the $\boldsymbol{C r}$ is small, the effect of the damping orifices as a meter-out circuit slows down the pilot valve response. When the $\boldsymbol{C r}$ is large, overdamping due to an increase in the damping coefficient $\zeta$ slows down the response. Thus, the $\boldsymbol{C r}$ has an appropriate value in the range from 0.69 to 1.6.

In step response characteristics, when the $\boldsymbol{C r}$ is too small, the slow rise time slows down convergence toward the target value. On the other hand, when the $\boldsymbol{C r}$ is too large, overdamping due to fast rise time slows down convergence toward the target value. When the $\boldsymbol{C r}$ is within a certain range, both the rise time and convergence tend to be fast.

The findings obtained from our analytical verification as described above have also been verified by our experimental results.

\section{Nomenclature}

\begin{tabular}{|c|c|c|}
\hline Designation & Denotation & Unit \\
\hline$A_{S P L}$ & Spool Cross-sectional area & {$\left[\mathrm{m}^{2}\right]$} \\
\hline$D_{b}$ & Pressure & {$[\mathrm{Pa}]$} \\
\hline$D_{S P L}$ & Spool diameter & {$[\mathrm{m}]$} \\
\hline$D_{n}$ & Damping orifice diameter & {$[\mathrm{m}]$} \\
\hline$F_{F}$ & Flow force & {$[\mathrm{N}]$} \\
\hline$F_{S O L}$ & Solenoid thrust & {$[\mathrm{N}]$} \\
\hline$K_{S P}$ & Spring constant & {$[\mathrm{N} / \mathrm{m}]$} \\
\hline$K_{S O L}$ & Constant of solenoid thrust & {$[\mathrm{N} / \mathrm{A}]$} \\
\hline$L_{W}$ & Control orifice width & {$[\mathrm{m}]$} \\
\hline$L_{b n}, L_{b T} L_{N T}$ & Annular clearance length & {$[\mathrm{m}]$} \\
\hline$P$ & Supply pressure & {$[\mathrm{Pa}]$} \\
\hline$Q$ & Flow rate & {$\left[\mathrm{m}^{3} / \mathrm{s}\right]$} \\
\hline$\zeta$ & Damping coefficient & {$[-]$} \\
\hline$\lambda$ & Friction factor & {$[-]$} \\
\hline$\theta$ & Jet angle & [degree] \\
\hline$\delta$ & Radial clearance & {$[\mathrm{m}]$} \\
\hline$\mu$ & Viscosity & {$[\mathrm{Pa} \mathrm{s}]$} \\
\hline$\nu$ & Kinetic viscosity & {$\left[\mathrm{m}^{2} / \mathrm{s}\right]$} \\
\hline$\rho$ & Working fluid density & {$\left[\mathrm{kg} / \mathrm{m}^{3}\right]$} \\
\hline$k_{P}$ & Proportional gain & {$[-]$} \\
\hline$T_{I}$ & Integral time & {$[\mathrm{sec}]$} \\
\hline$\tau_{S O L}$ & Time constant & {$[\mathrm{sec}]$} \\
\hline$\beta$ & Coefficient of flow force & {$[\mathrm{N} / \mathrm{m}]$} \\
\hline$\Gamma$ & Coefficient of viscosity & {$[\mathrm{Ns} / \mathrm{m}]$} \\
\hline$C$ & Flow constant & {$[-]$} \\
\hline
\end{tabular}
$F_{i}$
Force
[F]
Pressure
$[\mathrm{Pa}]$

\section{References}

[1] S Miyakawa, C Yamashina, and $\mathrm{T}$ Takahashi. Development of Water Hydraulic Proportional Control Valve. The Fourth JHPS International Symposium on Fluid Power, ISBN4-931070-04-3, (C) Copyright JHPS, 1999 All rights reserved. Japan.

[2] F Yoshida, and S Miyakawa. Characteristics of Proportional Control Valve Using Tap Water. The 7th International Fluid Power Conference, Group H, 445456, 22-24 March 2010, Aachen, Germany.

[3] F Yoshida, and S Miyakawa. Dynamic Characteristics of Proportional Control Valve Using Tap Water Experimental Examination-. The Twelfth Scandinavian International Conference on Fluid Power, Vol. 2 469480, 18-20 May 2011, Tampere, Finland.

[4] F Yoshida, and S Miyakawa. Effect of Parameters on Frequency Characteristics of Proportional Control Valve Using Tap Water. The 8th JFPS international Symposium on Fluid Power in Okinawa, Japan, on October 25-28, 2011, CD-ROM. 